\title{
Uma nova morada: música e memória na criação poética de Rui Pires Cabral
}

\author{
Nuno Brito \\ Universidade da Califórnia em Santa Bárbara
}

\begin{abstract}
Resumo
Este estudo tem como objeto a criação poética de Rui Pires Cabral, centrando-se nos temas da música e da memória como elementos que transfiguram o espaço urbano, geradores de experiências múltiplas que povoam e intensificam a relação com a cidade. Partindo do estranhamento e da singularização, este trabalho pretende observar como estes elementos constroem um novo espaço e uma nova vivência do cenário urbano.
\end{abstract}

Palavras-chave: Rui Pires Cabral; poesia; música; memória; cidade.

Abstract: This study is focus on Rui Pires Cabral's poetic creation especially in the themes of the music and memory as elements that recreate the urban space, elements that create multiple experiences that dwell and intensify the relation with the city. This study analyses the singularization and estrangement trying to see how this elements recreate the space and a generate a new experience of the city.

Keywords: Rui Pires Cabral; poetry; music; memory; city.

Recebido em: $15 / 03 / 19$

Aprovado em: 30/07/19

Eu fiz das grandes cidades o meu desejo. Rui Pires Cabral. Geografia das estações. 1994.

A memória e a música são formas de habitar, de criar relações, de gerar espaços e intensificar vivências. Nisso um texto pode ser também um mapa vivo, uma textura e um tecido que se deixa penetrar por diferentes planos, por distintas dimensões: um mapa das nossas experiências mais plenas (um cruzamento constante de fogos, desejos, memórias e expetativas). Um espaço múltiplo cruzado por diferentes identidades e experiências. Pensemos no título da poesia completa de Rui Pires Cabral - Morada - e nas redes que esta poesia cria em torno da casa, do quarto, da estrutura e do habitar. Pensemos como habitar é também uma forma de nomear, de preencher com vida, com vivências, mas também percorrer um espaço físico com os nossos passos concretos, com as nossas decisões. Sempre uma forma de reescrever o espaço 
e nos reescrevermos nele. E aqui penso em Sophia de Mello Breyner, como andar (sobre a terra) é também uma forma de escrever. De produzir uma relação com o mundo, de mover-se, juntamente, com ele. Ou, doutra forma, de o habitar poeticamente.

Pensemos em Rui Pires Cabral. Em como na sua criação poética, música, memória e espaço se entrelaçam, criando um todo unitário, orgânico e vivo. (Dotado de um poder trasmutador), gerador de um espaço movente, em que as referências toponímicas e musicais se cruzam e são constantemente associadas à experiência da memória, a uma revisitação, a um encontro de tempos e experiências, cristalizados no poema. Na criação poética de Rui Pires Cabral, as memórias da infância, as memórias da juventude ou as memórias das viagens criam um roteiro que passa essencialmente pelo espaço urbano, espaço que se reflete em alguns dos títulos dos seus principais livros, como por exemplo: Longe da aldeia, Praças e quintais, Capitais da solidão ou Música antológica e Onze cidades. Falar da cidade na poesia de Rui Pires Cabral é falar de uma presença omnipresente, reiterada, uma força transfiguradora: A Cidade é o local possibilitador da experiência, e aqui, é sobretudo a experiência de viagem aquela que nos é mais presente, a experiência de deslocamento, trata-se de vivenciar a cidade como estrangeiro, mas também de habitar um espaço a que se pertence, habitar a cidade, também internamente: "A cidade não se esgota / sobre a pele, há imagens que levantam pedras / na memória" (CABRAL, 2015, 119). O espaço urbano torna-se em Rui Pires Cabral a concreção imagética de um estado interior: “A rua, uma imagem mental” (CABRAL, 2015, p. 244), ou ainda "Da Batalha à Boavista, / quilómetros de alcatrão e calçada pela rua / que só havia na nossa cabeça" (CABRAL, 1995, p. 9). Este é um espaço habitado a partir da memória, concretizado na memória, é a cidade cristalizada enquanto experiência interior. Lugar de uma expansão e de um contacto. Em diálogo com Pedro Eiras: "a cidade material, que existe, só faz sentido (e, na verdade, sentido tênue) quando se deixa traduzir numa "imagem mental", a conjugar memórias, emoções, ruínas, alegoria. Postula-se, sempre, que a cidade é real - mas a realidade deve ser confirmada pela memória, pela abstração, pelo teatro metafórico. Para mostrar a realidade da cidade, em suma, é preciso transfigurá-la" (EIRAS, 2011, p. 194).

Tal como o quarto, a cidade afirma-se como arquivo, mas neste caso arquivo de experiências, arquivo do possível, ela é o fundo circunstancial que é urgente habitar, esta é sobretudo uma cidade noturna, percorrida fisicamente à noite, mas também relembrada ou reescrita durante a noite, na "deriva / nocturna da memória" (CABRAL, 2015, p. 198). Há um percurso feito através desta memória noturna que possibilita uma corrente de associações intuitivas que se estabelece em cadeia: "Mas a noite / tinha passagens secretas, bastava seguir / os sinais" (CABRAL, 2015, p. 66).

As portas, as pedras, os sinais, os túneis, ou as grandes superfícies referem uma arquitetura urbana que se assume como espaço de circulação e armazenamento de uma memória involuntária: "mas a memória é uma rede de túneis / cheia de portas súbitas e imprevistos 
alçapões" (CABRAL, 2015, p. 244), ou ainda "quanto desalento / nas grandes superfícies / da memória." (CABRAL, 2015, p. 214). A cidade representa um percurso que é mantido vivo pela circulação veloz das recordações; a cidade mental só pode ser habitada com memórias, por isso mesmo ela também pode ser esquecida, desaparecer, esvanecer-se ou renascer. Perdemo-nos nas memórias como nos perdemos numa cidade. Esquecer é, então, perder a localização, perder por momentos o chão. Se há atalhos que conduzem a novas memórias, há também atalhos que conduzem ao esquecimento, a um espaço em dissolução: "é a própria razão que nos ilumina os atalhos / para o esquecimento" (CABRAL, 2015, p. 82).

A cidade de Rui Pires Cabral é com recorrência uma cidade desabitada, uma cidade que é urgente habitar; ela manifesta-se, quase sempre, como um espaço desumanizado, excessivamente geométrico e disfórico que recorda, por vezes, certa experiência urbana da poesia de Cesário Verde. Ela é assim, também, lugar de esvaziamento e símbolo de uma descompensação: "e são tão tristes as luzes / nos vidros do multibanco / quando não passa ninguém" (CABRAL, 2015, p. 294). Esta ausência de vida torna-se visível e sentida nos próprios suportes da cidade, os vidros e os muros; estéreis, esvaziados de comunicação, eles pedem ser preenchidos, habitados com um sentido: "Empurrado contra um muro sem palavras, eu riscava / o espaço todo à minha volta, riscava-o até à fronteira / nas grutas de sábado à noite" (CABRAL, 2015, p. 62), Povoar um muro sem palavras é preencher, fazer vibrar com vida, habitar com linguagem, possibilitar que a cidade fale poeticamente, que ela se afirme como lugar humanizado. Aquilo que os muros dizem é uma mensagem que fala ao interior de cada um dos seres - eu digo passa a ser também eu escuto - ; eu estou atento, eu piso a terra (emissor e recetor se nivelam sob um eu impessoal). "Eram mesmo para mim as mensagens que encontrei / nos muros de algumas cidades" (CABRAL, 2015, p. 48). O poema "Espaços em branco" mostra-nos o esvaziamento da cidade enquanto lugar que perde sentido, que se esvazia:

Ao fim da noite, no frio do táxi, pousas a cabeça no meu ombro - e assim entramos duma vez e inteiramente na nossa vida. Lá fora, pelo contrário, tudo perde realidade.

há em toda a parte um sossego abstracto, as ruas parecem pintadas - betão entre as árvores - numa tela baça. Vamos por lugares que não reconheço, a minha geografia é vaga

e omissa como a dos velhos cartógrafos que desenhavam um mundo cheio de espaços em branco. É onde estamos agora, num intervalo do mapa rente à primeira manhã que será a nossa e também a última (CABRAL, 2015, p. 209). 
A cidade perde realidade, esvazia-se de sentido, perde a sua ligação a um fio de vida. Ela afirma-se como "um mundo cheio de espaços em branco" que é urgente habitar, intensificar e estranhar. A cidade com música é outra cidade. Essa é a experiência do walkman. A música intensifica a relação com a cidade, acelera o transporte de memórias, é detonadora de movimento, fluxo e comunicação, ela torna a cidade uma experiência interna. Essa é a experiência de que nos fala a última estrofe do poema "Vila real":

Nós os três contra o ar duro do Marão, os braços em torno dos joelhos. Quase uma imagem para a música das cassetes que eu levava para todo o lado (alguma desenquadrada peça de Satie entre Polly Jean e Tom Waits a uivar como um cão). Tínhamos vindo à procura da neve debaixo dos troncos, atirámos pequenas pedras às fundações do vale. E como parece branco e nítido o inverno (CABRAL, 2015, p. 121).

A cidade enquanto experiência intensificada é também, aqui, uma continuidade ou a projeção física da música. A vivência da cidade não é a mesma com "Tom Waits a uivar como um cão". O poema "Walkman" do livro A super-realidade evidencia claramente esta transfiguração do espaço.

Sentado a fumar com os meus diabos em Santa Maria del Fiore, a música é uma janela aberta no escuro até às cinco da manhã, quando já não há outra estrada que me sirva.

Agora filtrado nos tímpanos, entre os versos, em Florença a vender as suas graças. Se ponho as mãos sobre os olhos, o mundo acaba e recomeça de três em três minutos, as pedras da catedral arrastadas na areia mole das canções. Na cidade vista de dentro do meu poço, vou aonde me leva o rio da noite, pela pulsação eléctrica até onde calha

(CABRAL, 2015, p. 60).

Através do movimento que lhe imprime, a música faz da cidade outra cidade, ela assumese como uma experiência de extrema intensidade física, cada canção inicia e encerra, em si mesma, uma experiência limite, cada uma traz consigo uma experiência irrepetível, e constitui um renascimento espacial e temporal da cidade, ela renasce, por isso, de três em três minutos, essa é, em Rui Pires Cabral, a experiência do walkman e da música no contexto urbano. A música transmuta, altera um estado, liquidifica, faz com que, internamente, as estruturas da cidade percam a sua densidade, perante a música, as pedras da catedral são arrastadas (o espaço 
torna-se líquido e fluido); manifesta-se, então, nesse momento a super-realidade que dá o nome ao livro. A realidade habitada, tocada por um novo tempo, a realidade estranhada e transportada pela música até uma nova dimensão sensível, também ela física. Através da super-realidade, tudo sugere ser já outra coisa. Só a música permite, por isso, que a cidade não se esvazie e fique desprovida de sentidos, só ela possibilita que a cidade não perca realidade. "Nenhum comboio nos leva / tão longe: uma cidade morta / vive ainda na rara canção" (CABRAL, 2015, p. 330), nenhuma experiência de viagem física pode ir tão longe como a experiência estésica e interior da música. A música intensifica a relação com o espaço, reconfigura-o: "Noites de tabaco com resina / de Marrocos, pequenos quartos / onde a música era enorme. As ruas pulsavam, eram coisas / mortais" (CABRAL, 2015, p. 285).

Apesar de proporcionadora de uma experiência única, levada nos bolsos para todo o lado, a música pode unir os diferentes espaços, aproximá-los, criar entre eles uma comunhão e assonância, uma zona de partilhas; assim, apesar de irrepetível, ela propicia também uma experiência de homogeneização: ouvir Tom Waits em Londres ou em Vila Real é fazer comunicar esses dois espaços, aproximá-los por um mesmo batimento: "E a partir de certa altura / todas as cidades se parecem" (CABRAL, 2015, p. 215).

À semelhança da memória, a música é descrita como uma experiência espacial, dotada da sua própria geografia urbana, da sua própria arquitetura; a música não só habita e transfigura a cidade, ela é também, em si mesma, uma experiência espacial, "Vai ser fácil encontrar nos esconderijos da música / um bom lugar para o sono" (CABRAL, 2015, p. 104), dimensão física evidenciada em títulos de poemas como "Sala de música", que potencia uma experiência sinestésica. A música manifesta-se assim, também, fisicamente como uma experiência corporal: "Eu sentia na garganta / os tambores do sangue e os prédios enfadonhos / pulsavam na taquicardia, caíam em desamparo / para a cova do meu peito" (CABRAL, 2015, p. 103).

Se a experiência da música é uma experiência de super-realidade, sem a música tudo perde realidade, o momento do fim da música despoleta, por isso mesmo, uma experiência disfórica: "Mas, depois / da música, era como se uma estrela / morresse de repente" (CABRAL, 2015 , p. 237). Esta é a mesma experiência que podemos encontrar no poema "La Musique" de Baudelaire: (o momento do fim da música aproxima-se à experiência de um limite, de uma quebra, da possibilidade de um novo começo da cidade).

La musique souvent me prend comme une mer!

Vers ma pâle étoile,

Sous un plafond de brume ou dans un vaste éther,

Je mets à la voile;

La poitrine en avant et les poumons gonflés

Comme de la toile

J'escalade le dos des flots amoncelés

Que la nuit me voile; 
Je sens vibrer en moi toutes les passions

D'un vaisseau qui souffre;

Le bon vent, la tempête et ses convulsions

Sur l'immense gouffre

Me bercent. D'autres fois, calme plat, grand miroir

De mon désespoir!

(BAUDELAIRE, p. 175)

Ver a cidade intensificada pela música é sempre ver a cidade como estrangeiro, estrangeiro do espaço e de si mesmo, mas também ir ao encontro a um contacto, em direção a um início, a uma fonte, é ver a cidade como se a víssemos pela primeira vez, habitar uma realidade extrema, só possível de encontrar internamente, uma experiência de super-realidade, uma experiência limite. Como nos diz Pedro Eiras, "O poema é esse lugar de resistência que insiste em dizer a cidade como estranha" (EIRAS, 2011, p. 174). A cidade de Rui Pires Cabral é estranha quando, transfigurada pela memória e pela música, mas também o é quando ela própria perde realidade $\mathrm{e}$ se esvazia de sentido. De novo o mapa com as zonas em branco da cartografia clássica. As duas formas fazem parte de uma visão primeira ou criação primeira que é o motor desse próprio estranhamento. Pensemos no poema "A cozinha misteriosa":

A cozinha era misteriosa à hora da sesta.

Havia panelas penduradas muito alto, na parede, e a mosqueira onde se guardava um queijo duro, curado com colorau.

A porta de trinco manhoso dava para as sombras da latada, num chão torto de lousas e seixos. (Nos troncos onde se criavam cogumelos, Algum gato vigiava os pequenos ruídos.)

Havia couves junto ao rego da água, amoresperfeitos, flores roxas que se fechariam ao princípio da noite. E lá mais para cima as figueiras, onde às vezes apareciam cobras e agora se fez uma estrada

(CABRAL, 2015, p. 51).

No estranhamento é o olhar da criança que é reproduzido, revisitado através da memória, esse é um olhar de suspensão temporal. Reproduzir esse primeiro olhar sobre as coisas é elevalas à escala de um presente absoluto. José Ricardo Nunes encontra na poesia de Rui Pires Cabral "um efeito de presentificação", pelo qual "o passado [...] é sempre visto na óptica do presente, ou seja, como um momento (que foi) presente" (NUNES, 2002, p. 116), 
Voltamos então a essa memória física, que possui, ela própria uma arquitetura análoga à da cidade, uma memória táctil, sinestésica e circular, captada e percorrida pelo corpo. Enquanto criadoras de uma nova arquitetura, a música e a memória transfiguram a cidade transformando-a numa experiência interna - através dela, as paisagens são organismos vivos, presenças em que o dentro e o fora se desvanecem, se despolarizam e se tornam líquidos. É este transporte e circulação que é mantido vivo na poética de Rui Pires Cabral. Habitar significa então nomear e renomear, tornar mais vívida uma experiência, possibilitar, enfim, uma nova morada. Uma casa mais ampla.

\section{Referências}

BAUDELAIRE, Charles. Les Fleurs du mal (1857) (Disponível em: http://fleursdumal.org/ poem/175. Acesso em: 5 mar. 2018.

CABRAL, Rui Pires. A super-realidade. S. 1: s. e., 1995.

. Morada. Porto: Assírio \& Alvim, 2015.

EIRAS, Pedro. Um certo pudor tardio: ensaio sobre os "poetas sem qualidades". Porto: Afrontamento, 2011.

NUNES, José Ricardo. 9 poetas para o século XXI. Coimbra: Angelus Novus, 2002.

\section{Minicurrículo}

Nuno Brito é Teaching Assistant na Universidade da Califórnia em Santa Bárbara, onde visa obter o doutoramento em Literatura Portuguesa e Brasileira. 